\title{
THE LEGAL STATUS OF ELECTION OFFICIALS IN THE STATE OF MONTANA
}

\author{
Alexey V. Szydlowski \\ Southern Federal University, Rostov-on-Don, Russian Federation
}

Introduction: the election law of the US states to date remains insufficiently studied not only in Russia but also abroad. This is due to the fact that the legal regulation of the electoral process in America is attributed to the powers of the states or municipalities, depending on the legal doctrine applied by the state - Cooley Doctrine or Dillon Rule, which objectively imposes a limit on its study and generalization. The purpose of the study is to acquaint a wide range of scientific community with the latest research in the field of the US election law in regard to the first in the domestic law full description of the organizers of elections and referendums at the state and municipal levels in the United States. The author reviews a wide range of regional and local legislation with references to the constitutional, legal and regulatory acts of the US States. The paper is part of a series that explores all fifty subjects of the American Federation and the District of Columbia. Procedure and methods of research: the author analyzes the constitutional and electoral legislation of the United States at the level of Montana at the beginning of 2019. The methodology of the study was the comparative law, formal-legal, formal-dogmatic, specific-sociological, empirical, dialectical, analytical methods, the systematic approach. Results: the information about the organizers of elections and referendums in Montana, which was not previously covered in the Russian scientific literature, is introduced into scientific circulation. The interpretations of certain provisions of the law and legal consciousness of the U.S election law and law enforcement practice are given. The gaps of the legislation requiring additional research are surfaced. The theoretical and practical significance lies in the generalization of both the established and the latest legal sources (constitutions, organic laws, federal laws, charters, by-laws and regulations) of the United States and the subject of the American Federation and the development of proposals for the enrichment of the Russian science and the formation of objective understanding of the processes taking place in the United States in the field of constitutional, electoral law and the state-building. Conclusions: for a systematic and comparative legal analysis the author proposed the review of the legislation on the organizers of elections and referendums of Montana, revealing the existing contradictions, from the point of view of the Russian researcher, which allows considering the full range of elements of the electoral legislation of Montana from a new angle, seeing new legal structures, previously unknown to the domestic statesmen and law enforcers.

Key words: election law of the United States, organizers of elections, Montana, election legislation, referendum, vote.

Citation. Szydlowski A.V. The Legal Status of Election Officials in the State of Montana. Legal Concept, 2019, vol. 18, no. 3, pp. 137-144. (in Russian). DOI: https://doi.org/10.15688/lc.jvolsu.2019.3.20

\section{ПРАВОВОЙ СТАТУС ОРГАНИЗАТОРОВ ВЫБОРОВ В ШТАТЕ МОНТАНА}

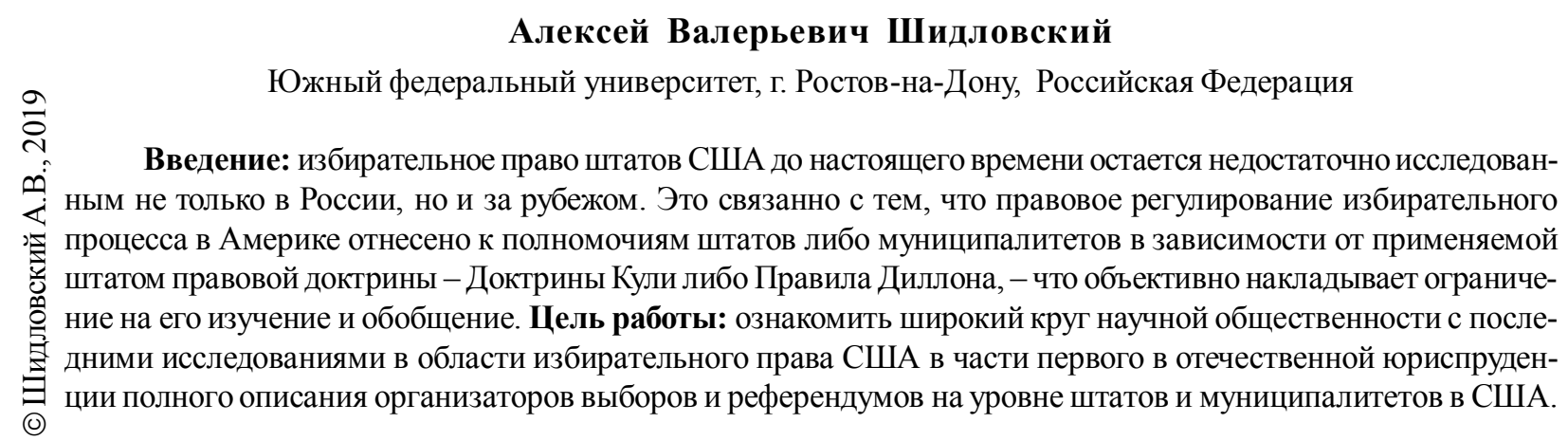




\section{МЕЖДУНАРОДНОЕ ПРАВО И СРАВНИТЕЛЬНОЕ ПРАВОВЕДЕНИЕ}

Автором делается обзор широкого массива регионального и местного законодательства со ссылками на конституционно-правовые и нормативно-правовые акты штатов США. Работа представляет собой часть из серии, исследующей все пятьдесят субъектов американской федерации и Округа Колумбия. Процедура и методы исследования: автором произведен анализ конституционного и избирательного законодательства США на уровне штата Монтана на начало 2019 года. Методологию исследования составили сравнительно-правовой, формально-юридический, формально-догматический, конкретно-социологический, эмпирический, диалектический, аналитический методы, системный подход. Результаты исследования: введена в научный оборот ранее не освещавшаяся в российской научной литературе информация об организаторах выборов и референдумов в штате Монтана. Даны интерпретации некоторых положений законодательства и правопонимания избирательного законодательства США и правоприменительной практики. Озвучены лакуны избирательного законодательства, требующие дополнительного исследования. Теоретическая и практическая значимость заключается в обобщении как устоявшихся, так и новейших юридических источников (конституций, органических законов, федеральных законов, хартий, подзаконных нормативно-правовых актов) США и субъекта американской федерации, и выработке предложений по обогащению российской науки и формированию объективного понимания происходящих в США процессов в области конституционного, избирательного права и государственного строительства. Выводы: автор предложил для системного и компаративного юридического анализа обзор законодательства об организаторах выборов и референдумов штата Монтана, вскрывающий имеющиеся противоречия, с точки зрения российского исследователя, что позволяет рассмотреть весь спектр элементов избирательного законодательства Монтаны под новым углом зрения, увидеть новые юридические конструкции, ранее не известные отечественным государствоведам и правоприменителям.

Ключевые слова: избирательное право США, организаторы выборов, Монтана, избирательное законодательство, референдум, голосование.

Цитирование. Шидловский А. В. Правовой статус организаторов выборов в штате Монтана // Legal Concept $=$ Правовая парадигма. -2019 . - T. 18, № 3. - C. 137-144. - DOI: https://doi.org/10.15688/lc.jvolsu.2019.3.20

\section{Введение}

Проблема изучения и обобщения локального и регионального законодательства, правоприменительной практики, конструкций, институтов и процедур, применяемых при организации избирательного процесса, актуальна не только для российских, но и для американских ученых. Качественные, порой диаметральные различия в законодательстве и правоприменительной практике регулярно возвращают юристов-исследователей в США к данной теме после каждого избирательного цикла, о чем свидетельствует и публикационная активность зарубежных коллег [4, с. $196 ; 5$, с. $244 ; 31$, с. $816 ; 32$, с. 176]. Продолжая компаративные исследования организаторов выборов на уровне штатов и муниципалитетов Соединенных Штатов Америки [1, с. 110; 2, с. 86; 3, с. 84], подробно рассмотрим круг лиц, занимающихся «администрированием» выборов и референдумов в штате Монтана.

\section{Организаторы выборов в штате Монтана}

Применяемый институт организаторов выборов: смешанная система электоральных офицеров и электоральной юстиции.
Органы и должностные лица - организаторы выборов: избирательная комиссия штата (The State Board of Election Supervisors), Государственный секретарь штата (The Secretary of State), Государственная комиссия счетчиков голосов (State Board of Canvassers), Государственный аудитор, Суперинтендант публичных инструкций, Генеральный прокурор штата, Администратор выборов (Election Administrator), Муниципальная комиссия аудита (County Audit Committe), Комиссия выпуска избирательных бюллетеней (Ballot Issue Committee), Муниципальная комиссия счетчиков голосов (County Board of Canvassers), Судебные коллегии по выборам (The Board of Election Judges), Комиссар по вопросам политической деятельности (Commissioner of Political Practices).

Юридическая техника законодателя штата Монтана по форме юридических конструкций, пожалуй, наиболее близка юридической технике российских правотворцев. Ее отличают наличие ясности и четкости понятий и определений, следование строгой юридической логике, присутствие нормативности в большинстве параграфов закона о выборах [6], инстанционность. Конструкция организаторов 
выборов штата представляет собой вертикально интегрированную систему с двумя контурами организаторов выборов - исполнителей и аудиторов. Верховным организатором выборов в Монтане является Государственный секретарь штата (The Secretary of State) [7]. Он же является главой всех организаторов выборов (The Chief Election Officer of This State) и правомочен осуществлять не только контроль за правоприменением законодательства о выборах, но и давать его официальное толкование, обладающее нормативными свойствами, а также принимать подзаконные нормативные акты по процедурным вопросам [8], утверждать стандарты форм заявлений (обращений) и отчетности [9], за исключением Части 13, Глав 35, 36, и 37 Закона о выборах, отнесенных к компетенции прокурора. Закон обязывает Государственного секретаря штата организовывать раз в два года профессиональную переподготовку организаторов выборов в муниципальных образованиях и проводить их итоговую аттестацию [10], а в процессе реализации последними их правомочий систематически осуществлять консультативно-методическую помощь. Органом надзора за правильностью подсчета поданных голосов на уровне субъекта федерации является Государственная комиссия счетчиков голосов (State Board of Canvassers), формируемая ex officio из Государственного аудитора, Суперинтенданта публичных инструкций и Генерального прокурора штата ${ }^{1}$. Государственный секретарь штата ex officio является техническим секретарем Государственной комиссии и осуществляет внесение итоговых решений комиссии в государственный реестр штата. К правомочиям комиссии отнесено установление итогов голосования и определение результатов выборов в штате [11]. Закон содержит норму, обязывающую Государственную комиссию счетчиков голосов провести собрание для реализации всех установленных законом процедур в течение 27 дней после дня голосования.

На уровне местного самоуправления организаторы выборов представлены четырьмя независимыми муниципальными органами: Администратор выборов (Election Administrator), Myниципальная комиссия аудита (County Audit Committe), Комиссия выпуска избирательных бюллетеней (Ballot Issue Committee) и Муниципальная комиссия счетчиков голосов (County Board of Canvassers). Администраторами выборов ex officio в каждом муниципалитете по общему правилу являются муниципальное должностное лицо, наделенное исполнительно-распорядительными правомочиями (County Clerk), и должностное лицо, наделенное исполнительно-распорядительными полномочиями органа местного самоуправления, в компетенцию которого входит запись актов гражданского состояния (County Recorder) при условии, что представительный орган местного самоуправления не наделил соответствующими полномочиями организатора выборов отдельное муниципальное должностное лицо [12].

Администраторы выборов обладают всей полнотой власти в пределах их компетенций, включая ведение реестра избирателей, исполнения и установления процедур, имплементации федерального и регионального законодательства. Муниципальная комиссия счетчиков голосов (County Board of Canvassers) по общему правилу ex officio формируется из всех руководящих лиц местного самоуправления (The County Govering Body) ${ }^{2}$ либо объединенного состава (Consolidated Local Government) высших муниципальных должностных лиц местного самоуправления и членов представительного органа местного самоуправления [13]. Закон содержит норму, наделяющую политические партии правом направлять членом комиссии по одному члену от местного исполнительного органа каждой политической партии, выдвинувшей кандидатов на текущих выборах. Комиссия правомочна только осуществлять надзор за возвратом бюллетеней из мест голосования, утверждать их количество и проводить формальную проверку протоколов итогов голосования [14], утверждать результаты выборов [15]. В случае, если избирательный участок не был открыт либо нарушения избирательного законодательства или процедуры не позволяют получить бюллетени и протоколы из места голосования, комиссия сообщает об этом Администратору выборов, являющемуся по общему правилу ее техническим секретарем. Администратор выборов составляет об этом соответствующую запись в итоговом протоколе. Правомочиями по вручению удостоверения кандида- 
та на выборную должность либо избранного муниципального должностного лица наделен Администратор выборов [16].

Избирательное законодательство штата Монтана содержит особенную норму, закрепленную Законом об обязательном поствыборном аудите (Postelection Audit Act), предусматривающую формирование независимого органа электорального аудита из независимых лиц, не имевших и не имеющих отношения к проводимым выборам [17], - Муниципальной комиссии аудита [18], которая правомочна отбирать случайным образом не менее $5 \%$ от общего количества избирательных участков для проверки правильности подсчета голосов. Правомочия комиссии реализуются в форме повторного ручного пересчета всех бюллетеней с каждого отобранного избирательного участка в течение 7 дней после дня голосования [19]. Закон содержит отдельную норму об обязательной публичности вышеуказанной процедуры электорального аудита.

Уникальной конституционно-правовой конструкцией Монтаны можно признать учреждение специальных муниципальных органов - Комиссий выпуска избирательных бюллетеней, правомочия которых вытекают из конституционного права граждан штата на законодательную инициативу через подачу петиций о включении их нормотворческих инициатив в бюллетени для голосования. Рассмотрение этого феномена выходит за рамки настоящей работы, поэтому ограничимся упоминанием о том, что к правомочиям настоящей комиссии отнесены вопросы рассмотрения петиций граждан на включение их инициатив в бюллетень, разработки и утверждения формы и дизайна бюллетеней и их типографская печать [20].

Первичное звено организаторов выборов в штате Монтана представлено электоральной юстицией - квазисудебным органом, состоящим из судебных коллегий по выборам (The Board of Election Judges) [21]. Электоральные судьи назначаются выборными должностными лицами местного самоуправления, аналогичного по составу Муниципальной комиссии счетчиков голосов, не менее чем за 30 дней до предварительных выборов в каждый високосный год на срок полномочий 4 г. [22] в составе судебной коллегии по выборам в количестве не менее трех судей. Правом выдвижения кандидатов в электоральные судьи наделены политические партии, обладающие правом выдвигать своих кандидатов на выборы в том же округе. Списки кандидатов, соответствующих установленным законом квалификационным требованиям, подаются местным отделением политической партии Администратору выборов, который в рамках своих дискреционных полномочий и пределах правоприменительного усмотрения осуществляет процедуру отбора кандидатов, в том числе единолично назначает председателя судебной коллегии [23]. При вступлении в должность электоральный судья приносит официальную клятву, предписанную конституцией [24]. Нормой закона также установлен запрет на исполнение судьей своих полномочий в случае наличия конфликта интересов, реализации пассивного избирательного права родственниками судьи по восходящей-нисходящей-параллельной линиям, супругов и пр. [25].

Надзор за соблюдением избирательного законодательства в штате Монтана отнесен к компетенции государственного должностного лица - Комиссара по вопросам политической деятельности (А Commissioner of Political Practices), назначаемого губернатором на срок полномочий 6 лет по представлению объединенного парламентского комитета в составе четырех членов: председателей обеих палат парламента и лидеров оппозиции обеих палат парламента. Парламентский комитет обязан представить губернатору список согласованных кандидатов, соответствующих квалификационным требованиям [26] для данной государственной должности, в количестве не менее двух и не более пяти кандидатов. После выбора кандидата губернатором номинированный кандидат должен быть утвержден простым большинством верхней палаты парламента [27]. Комиссар по вопросам политической деятельности является квазиследственным органом и правомочен проводить дознание и расследование, проводить иные следственные действия в пределах его компетенции [28]. Между тем Комиссар может быть привлечен к административной ответственности за служебный проступок прокурором округа либо вышестоящим прокурором [29], однако является специальным субъектом права и не может 
быть отстранен от должности общим порядком. Отстранение от должности Комиссара по вопросам политической деятельности может быть осуществлено только через процедуру импичмента [30].

\section{Выводы}

Настоящая работа предоставила для системного и компаративного юридического анализа обзор законодательства о выборах на уровне штата Монтана, позволивший рассмотреть весь спектр элементов избирательного права под новым углом зрения, позволяющего увидеть новые юридические конструкции, ранее скрытые от невооруженного глаза. Российскому научному юридическому сообществу, правоприменителю в лице избирательных комиссий всех уровней и законодателю следует внимательно ознакомиться с изложенным в работе уникальным опытом для возможной интеграции некоторых наиболее успешных юридических процедур и конструкций в отечественном законодательстве и правоприменительной практике. Автор акцентирует внимание российских юристов на трех юридических институтах, отсутствующих в современной России, но имеющих потенциал для имплементации в российское законодательство, - обязательном поствыборном аудите, наличии отдельного государственного (муниципального) органа, к компетенции которого отнесено рассмотрение вопросов о назначении референдума и электоральной юстиции. Детальный анализ текущего российского юридического ландшафта в области избирательного законодательства в корреспонденции с правоприменительной практикой наглядно иллюстрирует, что большую часть обоснованной критики правоприменителей вызывают вопросы правоотношений, связанные с контрольным подсчетом голосов, инициативой проведения референдума и порядком его назначения, а также с самим институтом избирательных комиссий и статусом их членов.

Таким образом, по мнению автора, имплементация указанных выше идей законодателя штата Монтана в российское правовое поле может позволить:

- распространить действующую в РФ норму об обязательном контрольном (ручном) подсчете голосов с не менее чем 5 \% избирательных участков, на которых подсчет голосов производился с использованием технических средств, на всю совокупность избирательных участков;

- создать комиссии выпуска избирательных бюллетеней как независимого государственного (муниципального) органа, ответственного за рассмотрение инициатив по проведению референдумов и порядок их назначения, и распространить указанную практику на уровень местного самоуправления относительно вопросов местного значения;

- повысить статус избирательных комиссий до уровня квазисудебных либо судебных коллегий, а статус членов комиссий до статуса федеральных судей в корреспонденции с уменьшением их численного состава.

С одной стороны, все вышеперечисленное позволит либерализовать законодательство о выборах и референдумах, с другой повысит качество организации избирательного процесса на первичном уровне и снимет критические замечания по данному поводу.

\section{ПРИМЕЧАНИЯ}

1 Должность Государственного аудитора штата представляет собой выборную государственную должность руководителя контрольно-ревизионного государственного органа штата; должность Суперинтенданта публичных инструкций представляет собой выборную государственную должность руководителя государственного органа штата, отвечающего за школьное и среднее профессиональное образование в штате Монтана (Montana Office of Public Instruction, учреждена в 1889 г.), и аналогична государственной должности министра образования в субъекте Российской Федерации.

${ }^{2}$ Стоит отметить, что в небольших по численности муниципалитетах отсутствует разделение муниципальных властей на исполнительно-распорядительную и представительную. Исходя из этого, законодатель штата Монтана предусматривает формирование Муниципальной комиссии счетчиков голосов из всех руководящих муниципальных должностных лиц, независимо от структуры организации органов местного самоуправления. Таким образом, в тех муниципальных образованиях, где установлено разделение муниципальных властей на исполнительно-распорядительную и представительную, Муниципальная комиссия счетчиков голосов формируется как из представителей исполнительно-распоряди- 
тельной ветви власти, так и из всех членов представительного органа местного самоуправления.

\section{СПИСОК ЛИТЕРАТУРЫ}

1. Шидловский, А. В. Доктрина Кули и Правило Диллона: современные проблемы американского избирательного права / А. В. Шидловский // Вестник Московского государственного областного университета. Серия: Юриспруденция. 2018. - № 3. - С. 107-123. - DOI: 10.18384/2310-67942018-3-107-123.

2. Шидловский, А. В. Круг выборных органов и должностных лиц в штатах США в разрезе федеративного устройства власти / А. В. Шидловский // Вестник Московского государственного областного университета. Серия: Юриспруденция. 2019. - № 1. - C. 82-100. - DOI: 10.18384/2310-67942019-1-82-100.

3. Шидловский, А. В. Организаторы выборов в штатах США. Айдахо, Айова, Аляска / А. В. Шидловский // Вестник Московского государственного областного университета. Серия: Юриспруденция. 2019. - № 3.- C. 82-104.

4. Damschroder, M. M. Of Money, Machines, and Management: Election Administration from an Administrator's Perspective / M. M. Damschroder // Election Law Journal. - 2013. - No. 12 (2). P. 195-202. - DOI: 10.1089/elj.2013.1225.

5. Mann, R. Re-Examining Indiana's Voter Id Law in Light of Recent Federal Court Cases: Where Does It Go From Here and What's Next for Indiana Election Law// Ind. L. Rev. - 2018. - Vol. 51. - P. 243-275.

6. Montana Title 13. Elections. - Electronic text data. - Mode of access: https://codes.findlaw.com/ $\mathrm{mt} /$ title-13-elections.

7. Montana Title 13. Elections $\S 13-1-201$. Chief Election Officer. - Electronic text data. - Mode of access: https://codes. findlaw.com/mt/title-13elections/mt-code-ann-sect-13-1-201.html.

8. Montana Title 13. Elections $§ 13-1-202$. Forms and Rules Prescribed by Secretary of StateConsultation. - Electronic text data. - Mode of access: https://codes.findlaw.com/mt/title-13-elections/mtcode-ann-sect-13-1-202.html.

9. Montana Title 13. Elections § 13-1-210. Standard Application Form for Voter Registration and Absentee Ballot Requests. - Electronic text data. Mode of access: https://codes.findlaw.com/mt/title-13elections/mt-code-ann-sect-13-1-210.html.

10. Montana Title 13. Elections § 13-1-203. Secretary of State to Advise, Assist, and Train. Electronic text data. - Mode of access: https://codes. findlaw.com/mt/title-13-elections/mt-code-ann-sect13-1-203.html.
11. Montana Title 13. Elections $\S$ 13-15-502. Composition and Meeting of Board of State Canvassers. - Electronic text data. - Mode of access: https://codes.findlaw.com/mt/title-13-elections/mtcode-ann-sect-13-15-502.html.

12. Montana Title 13. Elections $\S$ 13-1-301. Election Administrator. - Electronic text data. - Mode of access: https://codes. findlaw.com/mt/title-13elections/mt-code-ann-sect-13-1-301.html.

13. Montana Title 13. Elections $\S$ 13-15-401. Governing Body As Board of County Canvassers. Electronic text data. - Mode of access: https://codes. findlaw.com $/ \mathrm{mt} /$ title-13-elections/mt-code-ann-sect13-15-401.html.

14. Montana Title 13. Elections $\S 13-15-404$. Information to Be Entered on Record. - Electronic text data. - Mode of access: https://codes.findlaw.com/ $\mathrm{mt} /$ title-13-elections/mt-code-ann-sect-13-15-404.html.

15. Montana Title 13. Elections $\S 13-15-405$. Declaration or Certification of Results. - Electronic text data. - Mode of access: https://codes.findlaw.com/ $\mathrm{mt} /$ title-13-elections/mt-code-ann-sect-13-15-405.html.

16. Montana Title 13. Elections $\S$ 13-15-406. Certificates to Be Issued by the Election Administrator. Electronic text data. - Mode of access: https://codes. findlaw.com/mt/title-13-elections/mt-code-ann-sect-1315-406.html.

17. Montana Title 13. Elections $\S$ 13-17-504. County Audit Committee-Membership-Oath Required. - Electronic text data. - Mode of access: https://codes.findlaw.com/mt/title-13-elections/mtcode-ann-sect-13-17-504.html.

18. Montana Title 13. Elections $\S$ 13-17-502. Definitions. - Electronic text data. - Mode of access: https://codes.findlaw.com/mt/title-13-elections/mtcode-ann-sect-13-17-502.html.

19. Montana Title 13. Elections $\S 13-17-505$. Selection Process for Random-Sample Audit. Electronic text data. - Mode of access: https://codes. findlaw.com $/ \mathrm{mt} /$ title-13-elections/mt-code-ann-sect13-17-505.html.

20. Montana Title 13. Elections $\S 13-27-101$. Establishment of Initiative and Referendum Procedures. - Electronic text data. - Mode of access: https://codes.findlaw.com/mt/title-13-elections/mtcode-ann-sect-13-27-101.html.

21. Montana Title 13. Elections $\S$ 13-4-102. Manner of Choosing Election Judges. - Electronic text data. - Mode of access: https://codes.findlaw.com/ $\mathrm{mt} /$ title-13-elections/mt-code-ann-sect-13-4-102.html.

22. Montana Title 13. Elections $\S$ 13-4-101. Appointment of Election Judges. - Electronic text data. - Mode of access: https://codes.findlaw.com/mt/ title-13-elections/mt-code-ann-sect-13-4-101.html.

23. Montana Title 13. Elections $\S 13-4-102$. Manner of Choosing Election Judges. - Electronic text 
data. - Mode of access: https://codes.findlaw.com/ $\mathrm{mt} /$ title-13-elections/mt-code-ann-sect-13-4-102.html.

24. Montana Title 13. Elections $§ 13-4-105$. Oath of Judges. - Electronic text data. - Mode of access: https://codes.findlaw.com/mt/title-13-elections/mtcode-ann-sect-13-4-105.html.

25. Montana Title 13. Elections § 13-4-107. Qualifications ofElection Judges. - Electronic text data.Mode of access: https://codes.findlaw.com/mt/title-13elections/mt-code-ann-sect-13-4-107.html.

26. Montana Title 13. Elections § 13-37-107. Commissioner of Political Practices-Qualifications. Electronic text data. - Mode of access: https://codes. findlaw.com/mt/title-13-elections/mt-code-ann-sect13-37-107.html.

27. Montana Title 13. Elections $\S 13-37-102$. Creation of Office-Nomination-AppointmentRemoval. - Electronic text data. - Mode of access: https://codes.findlaw.com/mt/title-13-elections/mtcode-ann-sect-13-37-102.html.

28. Montana Title 13. Elections § 13-37-111. Investigative Powers and Duties-Recusal. - Electronic text data. - Mode of access: https://codes.findlaw.com/ mt/title-13-elections/mt-code-ann-sect-13-37-111.html.

29. Montana Title 13. Elections $\S 13-37-105$. Impeachment and Prosecution of Commissioner. Electronic text data. - Mode of access: https://codes. findlaw.com/mt/title-13-elections/mt-code-ann-sect13-37-105.html.

30. Montana Title 13. Elections § 13-37-102. Creation of Office-Nomination-AppointmentRemoval. - Electronic text data. - Mode of access: https://codes.findlaw.com/mt/title-13-elections/mtcode-ann-sect-13-37-102.html.

31. Moynihan, D. P. The Administrators of Democracy: A Research Note on Local Election Officials / D. P. Moynihan, C. L. Silva // Public Administration Review. - 2008. - Vol. 68. - No. 5. P. 816-827.

32. The Role of Dark Money Disclosure on Candidate Evaluations and Viability / S. C. Rhodes [et al.] // Election Law Journal: Rules, Politics, and Policy.2019. - P. 175-190.

\section{REFERENCES}

1. Szydlowski A.V. Doktrina Kuli i Pravilo Dillona: sovremennyye problemy amerikanskogo izbiratelnogo prava [Cooley Doctrine and Dillon's Rule: Modern Problems of U.S. Election Law]. Vestnik Moskovskogo gosudarstvennogo oblastnogo universiteta. Seriya: Yurisprudentsiya [Bulletin of Moscow Region State University. Series: Jurisprudence], 2018, no. 3, pp. 107-123. DOI: 10.18384/2310-6794-2018-3-107-123.
2. Szydlowski A.V. Krug vybornykh organov i dolzhnostnykh lits v shtatakh SShA v razreze federativnogo ustroystva vlasti [Us Electoral Bodies and Officials within the Framework of Federal System]. Vestnik Moskovskogo gosudarstvennogo oblastnogo universiteta. Seriya: Yurisprudentsiya [Bulletin of Moscow Region State University. Series: Jurisprudence], 2019, no. 1, pp. 82-100. DOI: 10.18384/ 2310-6794-2019-1-82-100.

3. Szydlowski A.V. Organizatory vyborov v shtatakh SShA. Aydaho, Ayova, Alyaska [Election Officials in the U.S. States.Idaho, Iowa, Alaska]. Vestnik Moskovskogo gosudarstvennogo oblastnogo universiteta. Seriya: Yurisprudentsiya [Bulletin of Moscow Region State University. Series: Jurisprudence], 2019, no. 3, pp. 82-104.

4. Damschroder, Matthew M. Of Money, Machines, and Management: Election Administration from an Administrator's Perspective. Election Law Journal, 2013, no. 12(2), pp. 195-202. DOI: 10.1089/ elj.2013.1225.

5. Mann R. Re-Examining Indiana's Voter Id Law in Light of Recent Federal Court Cases: Where Does It Go From Here and What's Next for Indiana Election Law. Ind. L. Rev, 2018, Vol. 51, pp. 243-275.

6. Montana Title 13. Elections. URL: https:// codes.findlaw.com/mt/title-13-elections.

7. Montana Title 13. Elections § 13-1-201. Chief Election Officer. URL: https://codes.findlaw. $\mathrm{com} / \mathrm{mt} / \mathrm{title}$-13-elections/mt-code-ann-sect-13-1201.html.

8. Montana Title 13. Elections § 13-1-202. Forms and Rules Prescribed by Secretary of StateConsultation. URL: https://codes.findlaw.com/mt/title13-elections/mt-code-ann-sect-13-1-202.html.

9. Montana Title 13. Elections \& 13-1-210. Standard Application Form for Voter Registration and Absentee Ballot Requests. URL: https://codes. findlaw.com/mt/title-13-elections/mt-code-ann-sect13-1-210.html.

10. Montana Title 13. Elections \& 13-1-203. Secretary of State to Advise, Assist, and Train. URL: https://codes.findlaw.com/mt/title-13-elections/mtcode-ann-sect-13-1-203.html.

11. Montana Title 13. Elections § 13-15-502. Composition and Meeting of Board of State Canvassers. URL: https://codes.findlaw.com/mt/title13-elections/mt-code-ann-sect-13-15-502.html.

12. Montana Title 13. Elections § 13-1-301. Election Administrator. URL: https://codes.findlaw. $\mathrm{com} / \mathrm{mt} /$ title-13-elections/mt-code-ann-sect-13-1301.html.

13. Montana Title 13. Elections § 13-15-401. Governing Body As Board of County Canvassers. URL: https://codes.findlaw.com/mt/title-13-elections/ mt-code-ann-sect-13-15-401.html. 
14. Montana Title 13. Elections § 13-15-404. Information to Be Entered on Record. URL: https:// codes.findlaw.com/mt/title-13-elections/mt-code-annsect-13-15-404.html.

15. Montana Title 13. Elections $\S 13-15-405$. Declaration or Certification of Results. URL: https:// codes.findlaw.com/mt/title-13-elections/mt-code-annsect-13-15-405.html.

16. Montana Title 13. Elections \& 13-15-406. Certificates to Be Issued by the Election Administrator. URL: https://codes.findlaw.com/mt/title-13-elections/mtcode-ann-sect-13-15-406.html.

17. Montana Title 13. Elections § 13-17-504. County Audit Committee-Membership-Oath Required. URL: https://codes.findlaw.com/mt/title-13elections/mt-code-ann-sect-13-17-504.html.

18. Montana Title 13. Elections \& 13-17-502. Definitions. URL: https://codes.findlaw.com/mt/title13-elections/mt-code-ann-sect-13-17-502.html.

19. Montana Title 13. Elections § 13-17-505. Selection Process for Random-Sample Audit. URL: https://codes.findlaw.com/mt/title-13-elections/mtcode-ann-sect-13-17-505.html.

20. Montana Title 13. Elections \& 13-27-101. Establishment of Initiative and Referendum Procedures. URL: https://codes.findlaw.com/mt/title13-elections/mt-code-ann-sect-13-27-101.html.

21. Montana Title 13. Elections § 13-4-102. Manner of Choosing Election Judges. URL: https:// codes.findlaw.com/mt/title-13-elections/mt-code-annsect-13-4-102.html.

22. Montana Title 13. Elections § 13-4-101. Appointment of Election Judges. URL: https://codes. findlaw.com/mt/title-13-elections/mt-code-ann-sect13-4-101.html.

23. Montana Title 13. Elections § 13-4-102. Manner of Choosing Election Judges. URL: https:// codes.findlaw.com/mt/title-13-elections/mt-code-annsect-13-4-102.html.

24. Montana Title 13. Elections $\$ 13-4-105$. Oath of Judges. URL: https://codes.findlaw.com/mt/title-13elections/mt-code-ann-sect-13-4-105.html.

25. Montana Title 13. Elections \& 13-4-107. Qualifications of Election Judges. URL: https://codes. findlaw.com/mt/title-13-elections/mt-code-ann-sect13-4-107.html.

26. Montana Title 13. Elections § 13-37-107. Commissioner of Political Practices-Qualifications. URL: https://codes.findlaw.com/mt/title-13-elections/ mt-code-ann-sect-13-37-107.html.

27. Montana Title 13. Elections § 13-37-102. Creation of Office-Nomination-AppointmentRemoval. URL: https://codes.findlaw.com/mt/title-13elections/mt-code-ann-sect-13-37-102.html.

28. Montana Title 13. Elections \& 13-37-111. Investigative Powers and Duties-Recusal. URL: https://codes.findlaw.com/mt/title-13-elections/mtcode-ann-sect-13-37-111.html.

29. Montana Title 13. Elections § 13-37-105. Impeachment and Prosecution of Commissioner. URL: https://codes.findlaw.com/mt/title-13-elections/mtcode-ann-sect-13-37-105.html.

30. Montana Title 13. Elections § 13-37-102. Creation of Office-Nomination-AppointmentRemoval. URL: https://codes.findlaw.com/mt/title-13elections/mt-code-ann-sect-13-37-102.html.

31. Moynihan D.P., Silva C.L. The Administrators of Democracy: A Research Note on Local Election Officials. Public Administration Review, 2008, Vol. 68, no. 5 , pp. 816-827.

32. Rhodes S.C. [et al.]. The Role of Dark Money Disclosure on Candidate Evaluations and Viability. Election Law Journal: Rules, Politics, and Policy, 2019, pp. 175-190.

\section{Information about the Author}

Alexey V. Szydlowski, International Electoral Expert of the OSCE, International Observer for the US Presidential Elections in 2012 and 2016 from Russia, Lecturer of the Department of State (Constitutional) Law, Southern Federal University, Gorkogo St., 88, 344000 Rostov-on-Don, Russian Federation, szydlowski@sfedu.ru, https://orcid.org/0000-0002-3923-3552

\section{Информация об авторе}

Алексей Валерьевич Шидловский, международный электоральный эксперт ОБСЕ, международный наблюдатель на выборах Президента США в 2012 и 2016 гг. от России, преподаватель кафедры государственного (конституционного) права, Южный федеральный университет, ул. Горького, 88, 344000 г. Ростов-на-Дону, Российская Федерация, szydlowski@sfedu.ru, https://orcid.org/0000-0002-3923-3552 